MATEC Web of Conferences 25, 01012

(2015)

DOI: $10.1051 /$ matecconf/ 20152501012

(c) Owned by the authors, published by EDP Sciences, 2015

\title{
Effect of Cascade Reservoirs on Flood Routing in the Hongshui River, Southern China
}

\author{
Kang Zhang, Shenguang Fang, Shaobo Wang \& Yanyan Zhang* \\ Research Center on Pearl River Estuary \& Coast Engineering of the Ministry of Water Resources, Guangzhou, \\ Guangdong, China \\ Pearl River Hydraulic Research Institute of the Pearl River Water Resources Commission, Guangzhou, \\ Guangdong, China \\ Wenming Zhang \\ Flood Control and Drought Relief Office of the Pearl River Water Resources Commission, Guangzhou, \\ Guangdong, China
}

\begin{abstract}
Hongshui River, with a length of $659 \mathrm{~km}$ and drainage area of $130,870 \mathrm{~km}^{2}$, is the upstream reach of Xijiang River, which is the dominant branch river of the Pearl River system in Southern China. There are 9 dams with a total storage capacity of $384.9 \times 10^{8} \mathrm{~m}^{3}$ constructed on the Hongshui River and its upstream reach Nanpan River since 1980s (the annual water discharge of Hongshui River is $696 \times 10^{8} \mathrm{~m}^{3}$ ). The water level of the 9 reservoirs is connected together, which causes the riverbed channelizing and the flood characteristic changing during the processes of flood routing. To study the effect of the cascade reservoirs on flood routing, 363 flood peaks data of two hydrologic stations on the Hongshui River during 1971 - 2007 are collected to analyze the flood characteristics changing before or after construction of the large dam Yantan. The flood peak travel time is the main factor which is taken into consideration in this study. Statistics results show: (1) The flood peak travel time which varies with flood magnitude shows different trends before and after construction of the Yantan dam; (2) the average flood peak travel time with a smaller flood magnitude $\left(<\mathrm{Q}_{\mathrm{P}=50 \%}\right)$ is shorter in the post-Yantan dam period than in the pre-Yantan dam period. However, the flood peak travel time with a relatively larger flood magnitude $\left(>\mathrm{Q}_{\mathrm{P}=50 \%}\right)$ has no obvious differences before and after the construction of Yantan dam.
\end{abstract}

Keywords: cascade reservoirs; flood routing; flood peak travel time; flood magnitude; Hongshui River

\section{INTRODUCTION}

Dam construction can supply human fresh water, irrigation, navigation, hydropower generation, and also can help human to control the flood and storage of sediment. However, the construction of dams disrupts the balance of natural rivers, which commonly cause a series of changes, such as water discharge or hydrology circles (Dynesius and Nilsson, 1994; Poff and Hart, 2002; Toping et al. 2003), sediment load (Topping et al. 2000), water quality (Poff et al. 1997), ecological connectivity (Ward and Stanford, 1995; Whol 2004), river ecology (Ligon et al. 1995), geomorphology (Turner 1971; Graf 2006), fluvial processes (Williams and Wolman, 1984), riparian plants (Turner and Karpiscak, 1980).

The hydrological regime is a central important factor in river systems, which is taken much attention of researchers. Most researches focus on the magnitude, frequency, duration, timing, and rate of change of hydrologic regimes (Walker et al. 1995; Magilligan and Graber, 1996; Poff et al. 1997; Yang et al. 2004; Magilligan and Nislow, 2005; Graf, 2006). Batalla et al. (2004) analyzed hydrological alternations in the Ebro River and its tributaries in northeastern Spanish,

*Corresponding author: yy zhang08@163.com where 187 reservoirs regulated $57 \%$ of the mean annual runoff. Statistic method was used by the flow data of 38 gauge stations. The results showed that most middle or small magnitude of flood was reduced; especially the $\mathrm{Q}_{2}$ and $\mathrm{Q}_{10}$ decreased over $30 \%$ on average. However, the annual discharge had little change. Graf (2006) concluded that the huge reservoirs reduced $67 \%$ of annual flood peak discharge by comparison of 72 regulated and unregulated reaches from the analysis of 36 rivers with huge reservoirs constructed (the total storage capacity is $1.2 \times 10^{6} \mathrm{~m}^{3}$ ). The ratio of annual maximum flow discharge to the average flow discharge is decreased by $60 \%$, and the maximum daily runoff is reduced by $71 \%$. Grown and Marsh (2000) also got the similar conclusion by analyzing the data sets of 107 river gauge stations in southeastern Australia where 42 data from regulated gauges and 55 data from unregulated river reaches.

Many studies also concentrated on the dam-break flood routing or channel flood routing (Amein and Fang, 1970; Fread, 1984; Jin and Fread, 1997). Nevertheless, the effect of dams (especially cascade dams) on the flood routing is still not clear. How about the effect of dam construction on the propagation time of flood peak and flood magnitude? How about the al-

This is an Open Access article distributed under the terms of the Creative Commons Attribution License 4.0, which permits unrestricted use, distribution, and reproduction in any medium, provided the original work is properly cited. 




Figure 1. Hongshui River Basin and the distribution of main dams and gauge stations

Table 1. Characteristics of the 9 dams constructed on the Nanpan River and Hongshui River

\begin{tabular}{|c|c|c|c|c|c|c|c|c|}
\hline No. & Reservoir & River & $\begin{array}{l}\text { Annual } \mathrm{r} \\
\left(\mathrm{m}^{3} \cdot \mathrm{s}^{-1}\right)\end{array}$ & $\begin{array}{l}\text { ffCatchment } \\
\text { area }\left(\mathrm{km}^{2}\right)\end{array}$ & $\begin{array}{l}\text { t Normal water } \\
\text { level (als.) }\end{array}$ & $\begin{array}{l}\text { Regulation capaci- } \\
\text { ty }\left(\times 10^{8} \mathrm{~m}^{3}\right)\end{array}$ & $\begin{array}{l}\text { Date of beginning } \\
\text { construction }(\mathrm{y} / \mathrm{m} / \mathrm{d})\end{array}$ & $\begin{array}{l}\text { Date of impounding } \\
(\mathrm{y} / \mathrm{m} / \mathrm{d})\end{array}$ \\
\hline 1 & Yantan & Hongshui & R. 1760 & 106,580 & 223 & 10.5 & $1985 / 3$ & $1992 / 3$ \\
\hline 2 & Dahua & Hongshui & R. 1990 & 112,200 & 155 & 0.39 & $1975 / 10 / 28$ & $1982 / 5$ \\
\hline 3 & Bailongtan & Hongshui & R. 2020 & 112,500 & 126 & 0.047 & $1993 / 2$ & $1996 / 5$ \\
\hline 4 & Letan & Hongshui & R. 2050 & 125,964 & 112 & 0.46 & $2001 / 11$ & $2006 / 1 / 7$ \\
\hline 5 & Qiaogong & Hongshui & R. 2130 & 128,564 & 84 & 0.27 & $2005 / 11$ & $2008 / 4$ \\
\hline
\end{tabular}

Table 2. Main hydrologic stations on the Hongshui River



ternation of travel time in different flood magnitude? How about the impact of scale of construction of reservoir to the flood travel time? These questions will be discussed in this article. And the objective of this study can be used to better understand the effect of dams to the flood hydrology, which is beneficial to flood control.

\section{STUDY AREA}

Hongshui River, with a total length of $659 \mathrm{~km}$ from the confluence of Nanpan River and Beiban River to the confluence of Hongshui River and Liujiang River, has a drainage area of $130,870 \mathrm{~km}^{2}$. Hongshui River is the upstream stem reach of the Xijiang River, which is the dominant branch of the Pearl River (also called Zhujiang River) in southern China (Figure 1). The gradient of Hongshui River is about $1 \%$ and Hongshui River annually drains water of $69.6 \times 10^{9} \mathrm{~m}^{3}$ to the downstream, which is beneficial to develop hydropower. There are 6 dams constructed on the Hongshui River, and 3 dams are built on its stem branch tributary Nanpan River since 1980s. The characteristic of the 9 dams are listed on Table 1 .

This study mainly focused on the Hongshui River, where 6 dams centralized are arranged on the reach whose length is approximately $420 \mathrm{~km}$ from Longtan dam to Qiaogong dam (it not concluded the 3 dams built on Nanpan River). The back water of the series dams was connected together to form the cascade reservoirs on Honghui River. The main hydrologic stations were Tian'e, Du'an and Qiangjiang, as shown in Figure 1. The characteristics of these 3 hydrologic stations were listed in Table 2. 
EMME 2015

Table 3. Statistic results of flood peak travel time with different flood magnitude before and after construction of the Yantan dam

\begin{tabular}{|c|c|c|c|c|c|}
\hline \multirow[b]{2}{*}{ Flood magnitude $/ \mathrm{m}^{3} \cdot \mathrm{s}^{-1}$} & \multicolumn{2}{|c|}{ Pre-Yantan dam } & \multicolumn{2}{|c|}{ Post-Yantan dam } & \multirow[b]{2}{*}{$\begin{array}{l}\text {-Variation of the flood } \\
\text { peak travel time } / \mathrm{h}\end{array}$} \\
\hline & $\begin{array}{l}\text { Number } \\
\text { peaks }\end{array}$ & $\begin{array}{r}\text { dFlood } \\
\text { time } / \mathrm{h}\end{array}$ & $\begin{array}{c}\text { travelNumber } \\
\text { peaks }\end{array}$ & $\begin{array}{c}\text { r of floodFlood peak travel } \\
\text { time } / \mathrm{h}\end{array}$ & \\
\hline$<1000$ & 2 & 69 & 1 & 18.5 & 50.5 \\
\hline 1000-1999 & 18 & 56.2 & 7 & 28.8 & 27.4 \\
\hline $2000-2999$ & 30 & 54.9 & 22 & 32.4 & 22.6 \\
\hline $3000-3999$ & 35 & 45.4 & 22 & 31.4 & 13.9 \\
\hline $4000-4999$ & 33 & 46.4 & 29 & 38.1 & 8.3 \\
\hline $5000-5999$ & 19 & 46.4 & 29 & 38.1 & 8.3 \\
\hline $6000-6999$ & 14 & 45.1 & 13 & 38.7 & 6.5 \\
\hline $7000-7999$ & 14 & 41.1 & 10 & 37 & 4.1 \\
\hline $8000-8999$ & 12 & 39.6 & 11 & 36 & 3.6 \\
\hline $9000-9999$ & 9 & 44.6 & 3 & 42.2 & 2.4 \\
\hline $10000-12000$ & 8 & 34.4 & 9 & 38.9 & -4.5 \\
\hline$>12000$ & 14 & 41.9 & 5 & 38 & 3.9 \\
\hline Sum & 203 & -- & 160 & -- & -- \\
\hline Average & -- & 47.1 & -- & 34.6 & -- \\
\hline
\end{tabular}

\section{MATERIALS AND METHODS}

\subsection{Data}

To evaluate the impact of dams to the flood routing, flood records of 2 hydrological stations (Tian'e and Qianjiang) were collected. And 257 flood events were separated from 32 years flood records of $1971-2007$ (unfortunately the data of 1987 and the data in $1989-$ 1992 were lacked). There were 5 dams built on the Tian'e - Qianjiang reach of Hongshui River with a total length of $422 \mathrm{~km}$. They are Yantan, Dahua, Bailongtan, Letan and Qiaogong. The main characteristics of the 5 reservoirs were listed in Table 1 .

\subsection{Method}

As the Yantan dam was the largest dam on the Hongshui River in 1992 - 2006, which had a stronger influences than the other dams in this study area, all the flood events were separated into two series of 1971 - 1991 (Pre-Yantan dam period) and 1992 2007 (Post-Yantan dam period). Wherein 203 peaks were during $1971-1991$, and 160 flood peaks were during 1992 - 2007. The flood peak travel time was taken into consideration to depict the flood routing. Flood peak travel time means the time that the flood peak moves from Tian'e to Qianjiang. All the flood events affected by the intervening flood were excluded. Relationship between the magnitude of flood peaks and the flood peak travel time was learned based on the 257 flood events records in Tian'e and Qianjiang (203 peaks in $1971-1991$ and 160 peaks in $1992-$ 2007). The statistic results of flood peak travel time with different flood magnitude before and after construction of the Yantan dam were listed in Table 3.

To study the influences of Yantan dam on the flood characteristics in Honghui River, different magnitude of flood events in Qianjiang hydrologic station was analyzed. Four indexes as flood volume, average flood discharge, flood wave type, and duration of flood were used to illustrate the variation of the flood characteristics before or after the construction of Yantan dam.

The flood volume of each flood events can be calculated by the Equation 1:

$V=\int_{t_{0}}^{t} Q d t$

Where $V$ is the flood volume of the flood events $\left(\mathrm{m}^{3}\right) ; Q$ is the flood discharge $\left(\mathrm{m}^{3} \cdot \mathrm{s}^{-1}\right) ; t_{0}$ is the start time of the flood event (h).

The average flood discharge of the each flood events is calculated by the Equation 2:

$\bar{Q}=V / T$

Where $\bar{Q}$ is the average flood discharge of the flood event $\left(\mathrm{m}^{3} \cdot \mathrm{s}^{-1}\right) ; T$ is the flood duration of the flood event (h).

The flood wave characteristic could be quantified by the flood wave type which is defined as the ratio of flood peak to the average discharge in each flood events (Shen G. Q. et al. 2008). The greater the value of flood wave type is, the thinner the flood hydrograph is. Table 4 shows that the flood characteristics varied with different flood events before and after the construction of Yantan dam in Qianjiang station.

\section{RESULTS}

4.1 Impact of dam construction to the flood peak travel time

Figure 2 shows the relationship of flood peak travel time and different flood peak magnitude before or after construction of dams in Hongshui River. The solid circle "•" means the situation before construction of dams, and the unsolid triangle " $\Delta$ " means the situation after construction of dams. 


\section{MATEC Web of Conferences}

Table 4. Statistic results of flood events characteristic variation with different flood magnitude in Qianjiang station before and after construction of the Yantan dam

\begin{tabular}{|c|c|c|c|c|c|c|c|c|}
\hline \multirow{3}{*}{$\begin{array}{l}\text { Flood } \\
\text { magnitude } \\
/ \mathrm{m}^{3} \cdot \mathrm{s}^{-1}\end{array}$} & \multicolumn{8}{|c|}{ Variation before/after construction of the Yantan dam Change rate before/after construction of the Yantan dam/ $\%$} \\
\hline & \multicolumn{2}{|c|}{ Flood volume Average dis- } & \multicolumn{2}{|c|}{ Flood waveDuration of } & \multirow{2}{*}{ Flood volume } & \multirow{2}{*}{$\begin{array}{l}\text { Average } \\
\text { discharge }\end{array}$} & \multicolumn{2}{|l|}{ Flood wave } \\
\hline & $/ \times 10^{8} \mathrm{~m}^{3}$ & charge $/ \mathrm{m}^{3} \cdot \mathrm{s}^{-1}$ & type & flood $/ \mathrm{h}$ & & & type & 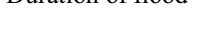 \\
\hline 1000-1999 & -3.537 & 67.327 & -0.009 & -76.182 & -36.0 & 4.8 & -0.8 & -39.2 \\
\hline $2000-2999$ & -1.691 & 317.584 & -0.108 & -39.278 & -11.8 & 16.2 & -8.4 & -19.9 \\
\hline $3000-3999$ & -8.827 & 295.359 & -0.180 & -114.578 & -41.0 & 11.6 & -12.8 & -47.3 \\
\hline $4000-4999$ & -10.985 & 562.094 & -0.178 & -131.959 & -35.6 & 18.2 & -12.3 & -46.4 \\
\hline 5000-5999 & -15.954 & 344.301 & -0.117 & -134.367 & -43.9 & 9.3 & -7.9 & -48.4 \\
\hline 6000-6999 & -11.430 & 109.560 & -0.082 & -81.197 & -25.3 & 2.4 & -5.5 & -28.4 \\
\hline 7000-7999 & -14.609 & 270.010 & -0.133 & -105.318 & -26.4 & 5.5 & -8.4 & -32.2 \\
\hline $8000-8999$ & -14.279 & 556.082 & -0.082 & -84.389 & -26.0 & 10.6 & -5.1 & -29.0 \\
\hline $9000-9999$ & -9.237 & 495.944 & -0.080 & -64.188 & -15.3 & 8.6 & -4.9 & -21.7 \\
\hline $10000-12000$ & -53.456 & -119.997 & -0.036 & -198.238 & -50.4 & -1.7 & -2.2 & -48.0 \\
\hline$>12000$ & -41.345 & -261.793 & -0.027 & -110.057 & -34.1 & -2.9 & -1.6 & -30.3 \\
\hline Average & -16.850 & 239.679 & -0.094 & -103.614 & -31.4 & 7.5 & -6.3 & -35.5 \\
\hline
\end{tabular}

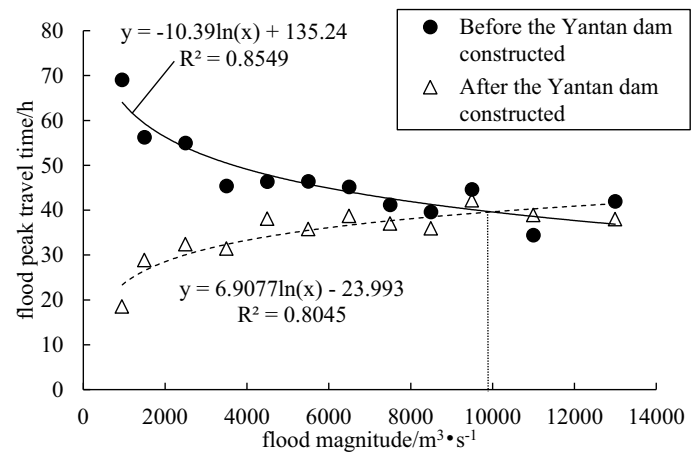

Figure 2. Alternation of propagation time of flood peak with different flood peak magnitude before and after the construction of dams

In Figure 2, the flood peak travel time showed a decreasing trend with the flood magnitude increase before construction of dams. The fitting curve was a logarithmic function and the correlation coefficient was 0.92 . However, the flood peak travel time was increased with the flood magnitude increase after the construction of dams. The changing trend of flood peak travel time was inversed after dam constructed.

For the medium and small flood, the flood peak travel time after construction of dams was shorter than before. Besides, for the large flood, the flood peak travel time after construction of dams had little changes compared with before. The critical magnitude of flood peak is about $10,000 \mathrm{~m}^{3} / \mathrm{s} \quad\left(\mathrm{Q}_{\mathrm{P}=50 \%}\right)$ in Hongshui River.
As shown in Table 3, the average flood peak travel time of all the flood events was $47.1 \mathrm{~h}$ before the construction of Yantan dam; however, the value was 34.6 $\mathrm{h}$ after the construction of Yantan dam. The flood peak travel time was shorter in post-Yantan dam period than in the pre-Yantan dam period.

Moreover, the change range of flood peak travel time with different magnitude flood was also quite different after construction of the Yantan dam. A ratio of the maximum flood peak travel time to the average flood peak travel time with each magnitude flood was used to quantify the change range of flood peak travel time. For the pre-Yantan dam period, the value was 1.5 , and the post-Yantan dam period was 1.2. Thus the change range of flood peak travel time was decreased after construction of the Yantan dam. It meant that the differentiation of flood peak travel time in each flood events was harder to claim.

\subsection{Impact of dam construction to the flood charac-} teristics

Figure 3 shows the variation of flood characteristics pre- or post-Yantan dam at different flood magnitude. Whether or not constructs the Yantan dam, the same trend is shown that the flood volume, average discharge, flood wave type and the flood duration of flood events are increased along with the increase of the flood magnitude. However, with a same flood magnitude, the flood volume, flood wave type and flood duration are decreased after construction of the Yantan dam. In Table 4, the average flood volume, flood wave type and flood duration of all flood events 

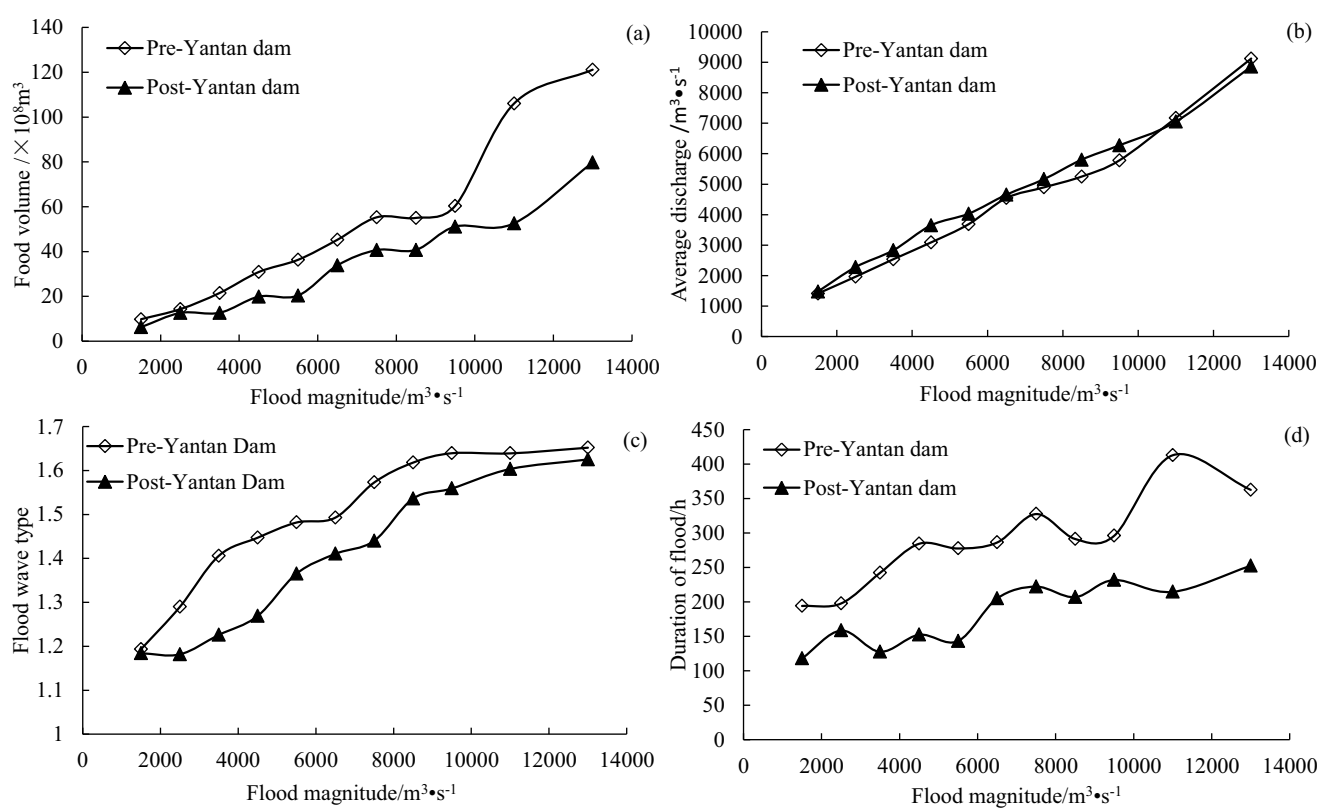

Figure 3. Flood events characteristics variation of different flood magnitude before and after construction of Yantan reservoirs in Qianjiang station (a) flood volume, (b) average flood discharge, (c) flood wave type, (d) duration of flood

are respectively decreased by $31.4 \%, 6.3 \%$ and $35.5 \%$ after the construction of the Yantan dam.

\section{DISCUSSION}

Dams on the Hongshui River mainly aimed to generate electricity. However, the dams on the Hongshui River also needed to follow the flood control operation in flood season. From Table 1, the Yantan dam was the largest dam on this section. As Yantan was a seasonal regulation reservoir, the Yantan dam is mainly used to regulate medium and small floods. When large flood come from the upstream, the reservoirs downstream could open the floodgate early, which caused the flood peak to arrive early downstream.

On the other hand, once the cascade reservoirs were built, the average channel water depth became deeper than before, causing the riverbed roughness to decrease and the flow velocity to increase. Thus the flood peak evolution was turned into flood wave propagation in the reservoir areas, which traveled faster than that in natural channel. This was also a reason for the flood peak.

\section{CONCLUSIONS}

Flood records of two gauge stations during 1971-2007 (data in 1987 and 1989-1992 are lacked) in the Hongshui River were used to analyze the alternation of flood magnitude and flood peak travel time before or after construction of the Yantan dam. 257 flood events with 363 flood peaks were used for statistical analysis. Results show that dams significantly affect the flood magnitude and flood peak travel time. The dams mainly hinder the large flood which causes the flood peak travel time decrease after construction of dams; however, for the medium and small flood, the flood peak travel time after construction of dams is shorter than before.

\section{ACKNOWLEDGEMENT}

This study is supported by the National Natural Science Foundation of China (GN. 51309264; GN. 51309263). Prof. Fengjun Xu in Pearl River Hydraulic Research Institute of the Pearl River Water Resources Commission gave many useful suggestions for improving this draft.

\section{REFERENCES}

[1] Amein, M \& Fang C S. 1970. Implicit flood routing in natural channels. Journal of Hydraulics Division, 96(12), 2481-2500.

[2] Batalla R J, Gomez C M, \& Kondolf G M. 2004. Reservoir-induced hydrological changes in the Ebro River basin (NE Spain). Hydrology, 290, 117-136.

[3] Fread D L. 1984. DAMBRK: The NWS dam-break flood forecasting model, National weather service, Office of Hydrology, Silver Spring, Maryland. 


\section{MATEC Web of Conferences}

[4] Graf W L. 2006. Downstream hydrologic and geomorphic effects of large dams on American rivers. Geomorphology, 79(3-4), 336-360.

[5] Graf W L. 2006. Downstream hydrologic and geomorphic effects of large dams on American rivers. Geomorphology, 79(3-4), 336-360.

[6] Grown J., \& Marsh N. 2000. Characterization of flow in regulated and unregulated streams in eastern Australia. Cooperative Research Centre for Freshwater Ecology Technical Report, 1-66.

[7] Jin Ming, \& Fread D L. 1997. Dynamic flood routing with explicit and implicit numerical solution schemes. Journal of Hydraulic Engineering, 123(3), 166-173.

[8] Ligon F K, Dietrich W E, \& Trush W J. 1995. Downstream ecological effects of dams, a geomorphic perspective. Bioscience, 45(3), 183-192.

[9] Magilligan F J. \& Graber B. 1996. Hydroclimatological and geomorphic controls on the timming and spatial variability of floods in New England, USA. Journal of Hydrology, 178: 159-180.

[10] Magilligan F J. \& Nislow K H. 2005. Changes in hydrologic regime by dams. Geomorphology, 71(1-2), 61-78.

[11]Poff N L, Allan J D, \& Bain M B, et al. 1997. The natural flow regime: a paradigm for river conservation and restoration. Bioscience, 47(11), 769-784.
[12] Shen Guanqing, Zhang Yuanfeng, \& Qu Shaojun, et al 2008. Influence of flood wave type on sediment transport in lower reaches of Yellow River. Journal of Hydraulic Engineering, 39(1): 7-13. (in Chinese with English abstract)

[13] Turner R M, \& Karpiscak M M. 1980. Recent vegetation changes along the Colorado River between Glen Canyon dam and lake Mead, Arizona. US Geological Survey Profession Paper, 1132.

[14]Turner, D.I., 1971. Dams and ecology. Civil Engineering 41, 76-80.

[15] Walker K F, Sheldon F, \& Puckrideg J T. 1995. A perspective on dryland river ecosystems. Regulated Rivers: Research \& Management, 11, 85-104.

[16] Ward J. C., \& Stanford J. A. 1995. Ecological connectivity in alluvial river ecosystems and its disruption by flow regulation. Regulated River: Research \& Management, 11(1), 105-119.

[17]Williams, G.P., \& Wolman, M.G., 1984. Downstream effects of dams on alluvial rivers. U.S. Geological Survey Professional Paper, vol. 1286. U.S. Government Printing Office, Washington, DC. 83 pp

[18]Wohl E. 2004. Disconnected rivers: linking rivers to landscapes. Yale University Press, New Haven. 301 pp.

[19] Yang Daqing, Ye Baisheng, \& Kane Douglas. 2004 Stream flow changes over Siberian Yenisei River Basin. Journal of Hydrology, 296(1-4), 59-80. 